\title{
Adaptation and adaptability in logistics networks
}

\author{
Competitive paper for IMP 2003
}

\author{
Associate Professor Marianne Jahre* \\ Professor Nathalie Fabbe-Costes**
}

\begin{abstract}
Taking its starting point in supply chain management relating it to the ARA-model for analysing changes in logistics resources, the paper concludes that there are trade-offs between adaptations and adaptability. The paper contributes to the understanding of system boundaries, integration problems and complementarities between chain and network approaches in logistics.
\end{abstract}

Keywords: adaptation, integration, system, logistics, network, supply chain, package, resource

*) Corresponding author

Department of Logistics, Norwegian School of Management - BI, 1301 Sandvika Norway. E-mail: marianne.jahre@bi.no, Phone: +47 67557353, Fax: +47 67557676

**) CRET-LOG, Centre de REcherche sur le Transport et la LOGistique, Université de la Méditerranée-Aix-Marseille II, Avenue Gaston Berger - 13625 Aix-en-Provence Cedex 1 France E-mail: nfc@univ-aix.fr, Phone: +33442939033, Fax +33442261732 


\section{INTRODUCTION AND PURPOSE}

Most logistics and supply chain management studies take (at least implicit) a 'systems view' where all functions/activities are to be understood by how they affect/are affected by other elements/activities with which they interact. According to Stock and Lambert (2001) 'systems must be viewed as a whole' (p.4), which requires that system-borders are set in order to be able to optimise the utilisation of resources by performing activities in an efficient manner. In the logistics literature the view on what are the relevant system-borders have changed over the years (Paché and Colin, 2000). According to Christopher (1992) 'real competition is not [any more] company against company but rather supply chain against supply chain' (p.14). Cooper et al (1997) go further and argue that it 'would be rare for a firm to participate in only one supply chain' (p. 9). In the same vein, Christopher (1998) suggests that supply chains could be viewed as networks, which would mean that activities are performed in relation to more than one chain. In line with this, Gadde et al (2002) suggest that a network view may complement the more common chain approach in the logistics literature.

Accordingly, system-borders, i.e. the 'whole', would look different depending on the perspective that is taken. One point of departure in this paper is therefore that it is not clear as to "what is the whole'. And if there are different 'wholes', what is then to be optimised? In the supply chain management approach it is important to obtain optimisation for the whole chain and avoid suboptimisations with regards to one company within a supply chain. Optimising often requires that activities are co-ordinated, integrated with and adapted to each other, with implications for also the actors and the resources involved. Weick (1982) suggests that there is a trade-off between adaptations and adaptability, his main point being that too much adaptation can lead to less adaptability, i.e. it is harder to change because more elements are adapted to each other and thus 
affected by a change. Another point of departure in the paper is thus to understand the difficulties of changing a well-integrated supply chain in accordance with a change introduced in the larger 'system', i.e. the network. According to Gadde et al. (2002) most logistics literature focus on inter-company integration of activities. The industrial network approach suggests that cooperation between companies, i.e. business relationships, can be described by three layers including activity links, actor bonds and resource ties (Håkansson and Snehota 1995). In accordance with Gadde et al. (2002) who suggest that a resource approach could complement the more common activity approach in logistics research, this paper takes the resource layer as the starting point, focusing on interfaces and adaptations between resource elements across organisational boundaries.

Accordingly, the purpose of this paper is, on the basis of a case study, to discuss trade-offs between adaptation and adaptability and to provide more understanding of the implications of the choice of system level with regards to the results that are obtained in the case of a resource change. Packaging forms the setting in which this question is discussed. The next section presents a theoretical framework on which the analysis of the case is based. Then the research design is described. The case is discussed and analysed with basis in the theoretical framework focusing on the question of adaptation and adaptability. The paper concludes with some main statements, limitations of the paper and some suggestions for further research.

\section{DEVELOPING THE THEORETICAL FRAMEWORK}

Four main theoretical starting points are presented including 1) differences between chains and networks; 2) differences between activities/actors and resources as focal starting point for case analysis; 3) the concept of trade-offs between adaptation and adaptability; and 4) the nature and usefulness of boundaries when considering a system. 


\section{From chains to networks}

An overview of the development of logistics from the 1960's up to the present shows that the 'whole' to be optimised has changed considerably. In the 1960's and 70's, companies didn't talk about logistics as it is defined today. They took care of physical goods because they had to and they did it with a technical approach related to logistics operations such as transport, warehousing and handling, resulting in very local optimisations. In the beginning of the 1980's, companies tried to optimise goods flows in order to cut logistics costs. They developed a three steps approach including the improvement of outbound (i.e. distribution), internal (i.e. production) and inbound (i.e. supply) flows. It then became obvious that the management dimension of those questions was as important as the technical ones. In the middle of the 80 's companies felt the need to optimise 'total' flow, to develop an overall process for managing information and goods flows and to structure an integrated logistics approach (at the company level). Step-by-step, companies understood the strategic power of logistics (Fabbe-Costes and Colin, 2003), but the optimisation was then restricted to the borders of the company. While developing integrated logistics, industrial and commercial firms began to outsource logistics operations to gain cost control and flexibility. They gradually left transport, storage, warehousing and order receiving in logistics providers' care. In the 1990's, logistics is seen as a competitive advantage as well as a complex process that cannot be restricted to the border of an individual company. It became obvious that in order to improve the overall logistics service offered to the end customer at minimum cost and with high flexibility, companies should co-operate and coordinate their activities. Thus, logisticians worked hard with downstream and upstream partnerships as well as with partnerships with their logistics providers (TPL). In line with this tendency, firms tried to develop Supply Chain Management (SCM), in the literature often defined as a network of firms 
that interact to manage flows, some focusing on physical aspects (e.g. Ellram, 1991), some more on organisational aspects (e.g. Christopher 1998).

When looking at the evolution of logistics, it is clear, as claimed by Paché and Colin (2000), that each new logistics 'step' (or 'era') corresponds to a change in 'the whole' to be optimised. The evolution moves forward from local optimisation (one activity) to intra-organisational optimisation (i.e. cross departmental inside a company), then to inter-organisational optimisation in 'external' dyads (i.e. supplier-customer relationships), 'external' chains (i.e. supply chain), and finally wide social optimisation that deals with safety, social, ethical and ecological objectives. Those many 'wholes' are still in competition today when looking at logistics/supply chain optimisation. Even if authors, in line with managers, don't agree on the definition of SCM and adopt various perspectives when they look at flow optimisation (see e.g. Cooper et al. 1997, Bechtel and Jayaram 1997, Larson and Dale 1998, Croom et al 2000, Mentzer et al. 2001, FabbeCostes 2002), the question of coordination between actors is always included. However, even if most practitioners and researchers admit that each company participates in more than one supply chain, it is a fact that SCM rarely deal with networks (i.e. multiple chains). And when it does, the 'network' is usually defined by a set of connected actors, i.e. key supply chain members (Cooper et al 1997, p.6). Further, a network defined in logistics terms would usually be a vertical and hierarchical one, and always defined from a focal actor's perspective - i.e. a 'network' includes numerous suppliers, suppliers' suppliers and numerous customers and customers' customers (Lambert et al 1998, p.3). For example, the links between the focal company's suppliers and the suppliers of other customers or the indirect links with TPL-providers are mainly disregarded (Fabbe-Costes and Brulhart, 1999). However, there seems to be agreement on that if operations are to be performed efficiently and effectively, they need to be co-ordinated and integrated, 
meaning that activities and actors must be closely coupled, see e.g. Mentzer et al. (2001, (p.17): 'reviewing the literature illustrated that supply chain management involves multiple firms, multiple business activities, and the coordination of those activities across functions and across firms in the supply chain'.

Whereas logistics/supply chain management is mostly concerned about activities and to some extent actors, the industrial network approach takes its starting point in how business units are connected by relationships through three layers - actor bonds, activity links and resource ties the ARA-model (Håkansson and Snehota, 1995). Actor bonds connect actors and influence how actors perceive each other and form their identities in relation to each other. Activity links regard technical, administrative, commercial and other activities of a company that can be connected in different ways to those of another company as a relationship develops. Resource ties connect various resource elements of companies and result from how the relationship has developed. The three layers are not independent, activities being carried out by actors through use of resources. The interplay of the three dimensions is a driving force in the development of business relationships. Further, connections between relationships, i.e. dyads, form a network. The connections can be direct, e.g. between a producer's relationship with a supplier and its relationship with its customer, but also indirect, e.g. the relationship to the customer is connected to relationships the customer has with its own customers or suppliers.

Accordingly, the industrial network approach complements supply chain management on at least two dimensions of great interest to us. First, they introduce the concept of indirect connections between relationships, not only the sequential (from raw material supplier via manufacturer, distributor to end-customer) linkages so common in the supply chain management approach. Second, they suggest a greater focus on resources for the formation and development of a 
network. The resulting 'network' is much more complex than the traditional logistics one and the consequences of any change (e.g. in a resource) are less easily predictable.

\section{From activities/actors to resources}

In general, logistics and SCM literature and practice first point out activities to perform in order to obtain efficient flows, then identify the actors who will perform the activities, and finally select the resources to use. Resources are thus mainly considered as tools. In line with a tendency in strategy (the resource-based view, see e.g. Wernerfeldt 1984), it is worth reversing the perspective and starting with resources. Obviously it is possible to consider supply chains in terms of inter-linked resources. In line with Penrose who claims that 'a firm is basically a collection of resources' $(1959$, p.77), we could claim that a supply chain or a logistics network is basically a set of more or less closely connected resources. Further, Penrose (1959) argues that the value of a resource is determined by the services it can render, i.e. that resources are heterogeneous. 'The services yielded by resources are a function of the way in which they are used - exactly the same resource when used for different purposes or in different ways and in combination with different types or amounts of other resources provides a different service or set

of services.'(p.25). Accordingly, the value of a resource can and will vary, depending on how it is used and particularly on the ways in which it is combined with other resource elements (Alchian and Demsetz, 1972). A resource can be used in different ways and its function can vary with time. Moreover, there are always alternative ways of using it as every resource has multiple features (Gadde and Håkansson, 2001). Such a perspective has been applied in a number of studies related to technological development as well as in marketing and purchasing. It is now also emerging in logistics (Gadde et.al 2002, Jahre and Hatteland 2003). According to these studies, technologies have systemic features, which affect all resource elements involved (Hughes 
1983, 1994). Consequently, resources can be more or less integrated. It appears that in supply chain management resources are systematically combined in terms of chains. However, these actual combinations tend to restrict the usage of the resource elements for other purposes. For example, a package can be looked upon as a logistics resource in the same way as an information system, a vehicle fleet, a terminal or a warehouse (Gadde et.al 2002). Because it plays numerous roles, it has interfaces with a number of other resources in a network including vehicles, handling equipment and warehouses, products and customers as well as return systems and raw materials (Jahre and Hatteland 2003). Thus, in line with the SCM perspective, a package has to be adapted to and integrated with these other resources in order to function in an efficient manner. What could be considered a small change at the resource level, for example changing the size of a package, could and probably would impact on a number of other resources in the logistics chain as well as in the network and may require changes in these too. Accordingly, adaptations to a specific supply chain for example make the package less useful in other applications and functions. In some situations the ties between the combined resource elements are very tight and therefore costly to change i.e. they inhibit adaptability and limit the use of the resource in another context. Starting with the resource thus seems to be a good approach for analysing trade-offs between adaptation and adaptability, for analysing implications of technological changes in a supply chain and to show that this question is related to the 'whole' taken into account.

\section{Adaptation and adaptability}

Logistics and SCM seek better integration of resources as well as a higher flexibility in the chains. Integration, i.e. closer adaptation, facilitates co-ordination of activities and leads to more efficient processes. Further, flexibility - i.e. adaptability or capacity to adapt - is necessary to face future changes. Weick (1982) claims that too much adaptation can lead to less adaptability, 
i.e. it is harder to change because more elements are adapted to each other and thus affected by a change. Andersson (1992) discusses the concept in relation to dynamic aspects of marketing channels, but it was developed originally in relation to 'intra-organisational' issues and is linked to another concept developed by Weick - the notion of organisations as 'loosely coupled systems'. To our knowledge the concept has not been applied within the logistics or supply chain management literature. With regards to the present focus on supply chain integration, this is somewhat surprising if we take into consideration that loose couplings may be seen as the opposite of system integration (Weick 1982, p. 381). One of his points is that whereas loose coupling is the source of adaptability, tight coupling is the source of most adaptation (Weick 1982, p.387). Uzzi (1997) argues that 'embeddedness assists adaptation because actors can better identify and execute coordinated solutions to organizational problems' (p.54). He introduces what he calls the 'paradoxes of embeddedness': 'the same processes by which embeddedness creates a requisite fit with the current environment can paradoxically reduce an organization's ability to adapt' (ibid. p.57). If one interprets the concept of embeddedness as tight coupling, Uzzi reaches the same conclusion as Weick: there is a trade-off between tight coupling and adaptation on the one hand and loose coupling and adaptability on the other. Of course, the issues related to this trade-off depend on the level of change one will have to face in the future since there is a need for adaptability only in cases of a change. Literature focusing on industrial flexibility points out two types of changes with different flexibility (adaptability) required. For example, Cohendet and Llerena $(1990,1999)$ define static flexibility to face predictable future with foreseeable changes you can anticipate and dynamic flexibility when future is definitely uncertain. The trade-off will also depend on the system you look at and its relation with its environment, the definition of boundaries being crucial. 


\section{Nature and usefulness of boundaries}

The systemic approach points out the question of boundaries of systems. When the studied system is an organisation, Avenier (1997, p.51-60) argues that boundaries are contingent, temporary, not impenetrable, related to intentions and projects of actors involved in it (or of researchers studying it). Boundaries are not given but created by actors who need them to picture and analyse situations and to make decisions. Managerial decisions and results will then mainly depend on the selected boundaries. Gadde and Håkansson (2001) are in line with this perspective: 'network boundaries are always arbitrary - they are based on perceptions and are continuously changed' (p.181). A logistics process or a supply chain crosses organisational boundaries and, as a system, has its own boundaries that are multiple, related to the willingness to manage flows boundaries that are not easy to define (Fabbe-Costes 1997, p.246-253). It is thus important when discussing trade-offs between adaptation and adaptability to be aware of 1) the system(s) considered - e.g. supply chain vs. network and 2) the boundaries of the system(s). Different system borders would most probably lead to different conclusions.

\section{RESEARCH DESIGN}

The empirical evidence in this paper is based on one of a number of case studies on packages as logistics resources in supply and distribution networks. Even if, in line with Piore (1992) we consider that 'technical change goes hand in hand with organisational change', we have chosen to focus on the technical dimension in this paper in order to debate on the trade-offs between adaptation and adaptability. The case starts out from a transport package as the focal resource and describes and analyses how it is connected to other resources in the network through a number of interfaces. Collection of data was performed in 2001-02 within the frame of reference used in a research project focusing on logistics resources and how they interface, are utilised and 
developed. A specific theoretical framework has been developed for the empirical studies within this NETLOG-project and is presented in Gadde et.al. (2002). The case study approach was chosen because the project is to 'create an understanding of relationships and complex interactions by the use of real world data' (Ellram 1996, p.97).

\section{CASE DESCRIPTION AND ANALYSIS}

The case takes as its focal a transport package - a roll rack which is a load carrier of metal with wheels - and how it is used in Tine's distribution of fresh milk. Together with two other suppliers of agricultural food produced in Norway (Gilde and Prior) Tine has formed a distribution partnership where products are transported through common regional terminals (owned by one of the three partners) out to each of Norway's four thousand five hundred stores. The case concerns a potential change of starting to utilise the roll-rack as the standard load carrier in the distribution network for all products from these three actors. Detailed descriptions of the case is provided elsewhere - see (Hatteland 2002, Jahre and Hatteland 2003). We focus on what happened as the potential change was initiated and try to explain why it was not implemented.

\section{The present use of the roll-rack in its logistics network}

Tine developed the roll-rack as their main load carrier for milk - the product in Tines distribution

constituting the largest turnover and volume. The roll-rack fits perfectly with the sales package of the milk product - 160 1-litre cartons distributed in four layers match the capacity of one rollrack in width, breadth and height. Other main resources, to which the roll-rack was developed to fit, include production facilities where the milk is filled into cartons and placed directly into the roll-racks for transportation as well as the terminals themselves. Concerning transport the main feature of the roll-rack is that it can easily be rolled in and out of the vehicles. Another feature of great importance is the adaptation to the cooling, storage and exposure facilities in the shops, and 
even at petrol stations. Finally, the way it can easily be transported, handled and stored also when empty is a feature of importance in reusable packaging systems. Accordingly, the analysis of the roll-rack shows that this package is well adapted to the main resources involved in Tine's milk distribution and as such is integrated in this logistics system. From the milk supply chain's point of view the roll-rack is closely adapted to other resources. This is quite in accordance with what is claimed in the literature saying that in order to be efficient, a package needs to be integrated with the logistics system and the activities involved (Ballou 1987, Bowersox and Closs 1996, Johnsson 1999, Stock and Lambert 2001). This system is illustrated in figure 1:

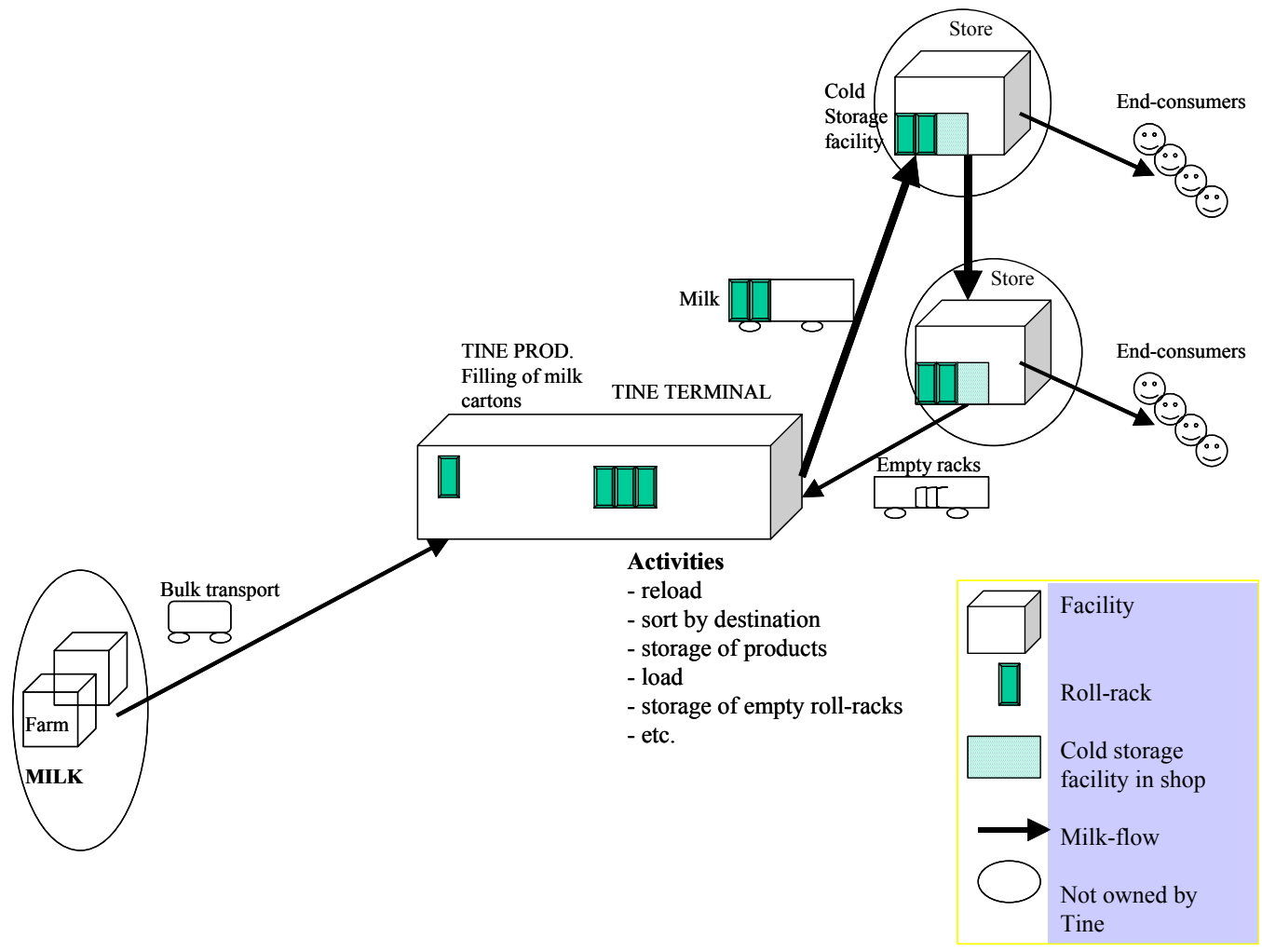

Figure 1: The milk supply chain and the use of the roll-rack

However, milk cartons are not the only products distributed and sold by Tine. First, there are close to one thousand other Tine products that use a number of other load carrying devices such as cardboard boxes, plastic through/trays and boards, cases/trays, pallets and other roll racks. 
These products are produced in other production facilities and have to be transported to the terminals, whereas milk is filled into cartons at their production facility located at the terminals (0). Second, Tine has to co-ordinate its activities with others companies in the network as illustrated in figure 2. When Tine, Gilde and Prior set up their common distribution system they chose a limited number of terminals, belonging to Tine or Gilde depending on which had the best location with regards to inbound as well as outbound logistics. Further, the shops in Norway are organised in four main retailer chains to which the three companies in our case as well as the respective shops must relate. Third, as new products are continuously being developed, there has been an enormous expansion of product design and product packaging.

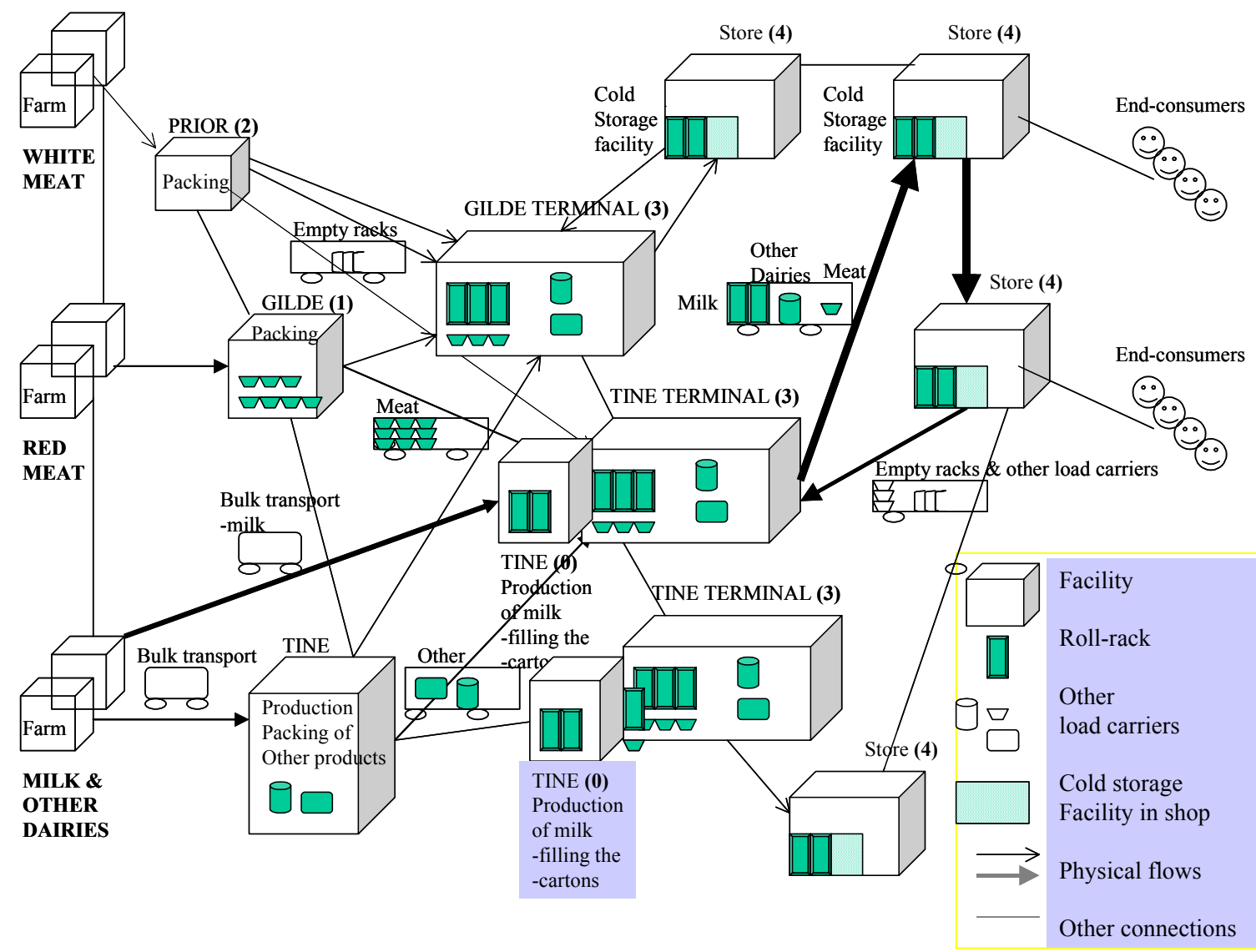

Figure 2: The milk supply chain as one of many supply chains in the distribution network 
The two other large actors in the Norwegian food market - Gilde (1) offering red meat products, Prior (2) offering white meat and eggs - distribute much of their products through the same network in sales packages that differ from the milk-cartons in size and format and in transport packages that differ from the roll-rack. When these other products arrive at the distribution centres (3), some are taken out of their original load carriers and reloaded into the roll-rack; some are loaded into the roll-racks in their original load carriers whereas others are transported to retailers as they are - on pallets or other load carriers. Hardly any of these products - whether they are reloaded into the roll-rack or not - use it for exposure in the shops. Products are therefore reloaded once more at the retailer level (4) into other exposure facilities. As we can see, looking at Tine's total supply chain including other products than milk, there is sub-optimisation (extra unloading and reloading with extra risks of product damage, extra logistics costs and extra lead time) because the roll-rack is not adapted to the other products distributed by Tine, let alone products distributed by Tine's partners or other resources involved in these logistics systems.

\section{The potential change in use of the roll-rack and the result so far}

As the roll-rack is such an efficient package in Tine's milk supply chain, Tine would like to extend its use, for its own products as well as for their partners', and make it a standard loadcarrier in the network. However, then more loading and reloading would be required or these other products' sales packages would have to change as well as a number of other resources in the other systems that together form the network. Alternatively, or probably as well, the roll-rack would also have to be changed. At first glance, the roll-rack does not seem very difficult or costly to change. Because of the numbers used - approximately 110.000 -costs of not more than NOK 2500 per unit on the average still amounts to quite a large sum if all roll-racks were to be replaced or changed. Technically it seems relatively straightforward to change its design, but profound 
changes in the roll-rack would probably require changes in Tine's logistic system for the large volumes of milk, possibly also in the milk sales package itself and even in the milk production facilities as well as in the systems for their partners. Accordingly, so far the discussion on using the roll-rack as a standard has not resulted in any decision. Replacing one load carrier with another does not only require investments in load carriers, but investments in redesigning the resources with which the roll-rack has interfaces. It would also require changes in how activities are performed at one or more partners in the distribution 'alliance' as well as at different members of the supply chains - producers, distributors, wholesalers and retailers.

\section{DISCUSSION AND CONCLUSIONS}

We have provided an example of a logistics resource that is well integrated and adapted to other resources in a specific supply chain. However, as milk is only one of many products in the logistics network, the efficiency of the roll-rack in the network and for Tine, depends on its adaptability to other load carriers used for other products. Poor interfaces with other load carriers imply reloading and more handling at terminals and in retail shops, with adverse consequences on vehicles stop times. If products are not reloaded into the roll-rack, capacity utilisation of the transport vehicles becomes less efficient because the load carriers do not "fit" with each other. As they require different equipment and routines for handling, these operations too become less efficient. We see that the value of the roll-rack as a resource for Tine is determined by its adaptations to a number of other resources in the network, and not only the resources in the 'milk-chain'. As for any package, the number of interfaces is huge because it moves around in the network with according impact on how activities can be performed by a number of different actors. What the case had shown us is that because the roll-rack was designed specifically for distribution of milk, it is not well adapted to the distribution of the other products. As the roll- 
rack replaced the load-carrier for milk in the old system, as milk was the by far most important product for Tine and as they did not have distribution partnerships with other companies, the rollrack was designed to fit Tine's at the time existing logistics system for milk. Then the logistics systems of the three partners were relatively independent of each other and did not meet until the products reached the shops. As Tine started to diversify and co-operate with the other companies, the roll-rack became part of a larger network involving an increased number of interfaces with other technical (and organisational) resources. Accordingly, the question of adaptability became important and the roll-rack seemed less efficient a logistics resource than before. Even if it is well integrated with Tine's logistical system for milk, the 'milk-chain' is (now) only (a small) part of the network and in fact only one of the 'systems' that Tine operates. Accordingly, the analysis illustrates how trade-offs between adaptation and adaptability relate to system levels, development over time and degree of adaptation:

- The milk supply chain, Tine's supply chain and the logistics network including the partners constitute different system levels and shows how a well-adapted and optimised resource at one level appears to be less suitable at another. The choice of different system boundaries will impact on how one and the same resource is looked upon with regards to adaptation and optimisation. In a logistics network, you can focus on specific supply chains (e.g. the rollrack milk chain), a specific logistics network (e.g. Tine's network) or a more complex network (e.g. including distribution partners).

- Because of continuous development (of companies, products, customers, regulations, strategies of competitors, etc.) a very well adapted resource at time t, will be unsuitable at time $\mathrm{t}+$ and its adaptability with regards to the new context will be questioned. As many changes are unavoidable and unpredictable, dynamic flexibility as defined in Cohendet and 
Llerena $(1990,1999)$ is required. Adaptation could be viewed as a 'temporary equilibrium', the question of equilibrium being a corner stone in the systemic approach and now also being discussed in logistics (Fabbe-Costes and Lièvre, 2002).

- The more adapted a resource, at a certain level and a certain time, is, the more difficult it is to change and adapt to a new context. We see that because the roll-rack is so adapted to the other resource elements in the milk supply chain, Tine does not want to do major changes, but rather have other systems and products adapting to the roll-rack milk chain. In the same way Gilde and Prior do not want to replace their own carriers with the roll-rack as their load carriers are adapted to the other resources in their specific systems. Changing would be costly and would probably lead to less optimisation at the local level. The case illustrates the irreducible conflict between, on the one hand, close adaptation of resources in order to perform efficient logistics and, on the other hand, the necessity of adaptability to face future development.

From a methodological viewpoint, we find that basing the analysis on resources is interesting in order to understand the impacts of a potential change with regards to the question of adaptation and adaptability. In particular, physical resources seem to be a good starting point as changes are relatively easy to observe and to discuss. Finally, choosing a transport package as the focal resource is interesting from a logistics viewpoint as they are so crucial in logistics systems. Packages are also interesting from an industrial network approach as they have a large number of interfaces with other elements since they move around. It seems that to view logistics as resource ties in networks can complement the existing approach of looking at activities in chains when it comes to the understanding of why integration can be difficult, why companies have large 
problems in implementing the integrated supply chain concept and why this may even be a dangerous concept to apply.

However, there are some limits to the research we have presented in this paper. One is that we base our discussion on one single case - further research could provide other cases in order to elaborate more on the research issues in question. Another limitation is that we pose new questions rather than giving answers as to how companies should manage the trade-off between adaptation and adaptability. We conclude that adaptations do take place, that they are rational from certain points of view and that adaptability is also necessary because of continuous changes. We do not discuss the question of how to adapt. However, a perhaps more interesting research issue is found in Weick's own concern about applying a one-dimensional understanding of the concept of loose coupling and how it relates to adaptability, because 'loose coupling, ......combine the contradictory concepts of connection and autonomy', because tight coupling can facilitate adaptability under certain conditions (e.g. can they communicate quicker than loose coupled system) and loose coupling may also produce adaptation under specific circumstances (Orton and Weick 1990, p. 216). An interesting question for further research is therefore whether simultaneous loose and tight coupling is possible, i.e. how can we obtain adaptation and adaptability at the same time? In logistics this would translate to how we simultaneously can optimise individually two systems that are part of the same network, and still obtain an overall efficient solution. Is the answer to 'loosen up', i.e. to disintegrate logistics systems, or do we have to differentiate between system levels focusing on tight couplings between a limited number of resources and loose ties between these couplings? As it is 'impossible to come up with a 'master network strategy' taking every aspect into consideration...[thus] strategies are always partial and they are valid only for the time being, and must continuously be changed and altered 
(Gadde and Håkansson, 2001, p.183), we claim that a complementary approach to optimising the 'whole' in terms of integrated supply chains is required. 


\section{REFERENCES}

Alchian, A. and Demsetz, H. (1972), "Production, Information Costs and Economic Organization", The American Economic Review, 62, pp. 77-95.

Andersson, P. (1992),"Analysing Distribution Channel Dynamics: Loose and Tight Coupling in Distribution Networks", European Journal of Marketing, Vol 26, No 2, pp. 47-68.

Avenier, M.J. (1997), La stratégie "Chemin Faisant", Economica, Paris, 1997.

Ballou, R. H. (1987), Basic Business Logistics: Transportation, materials management, physical distribution, Prentice-Hall, Englewood Cliffs.

Bechtel, C. and Jayaram, J. (1997), "Supply chain management: a strategic perspective", The International Journal of Logistics Management, Vol.8, $\mathrm{n}^{\circ} 1$, pp.15-34.

Bowersox, D. J. and Closs, D.J. (1996), Logistical Management - the Integrated Supply Chain Process, McGraw-Hill Companies, Inc.

Christopher, M. (1992), Logistics and Supply Chain Management - Strategies for reducing Cost and Improving Service, Financial times Professional Ltd., London.

Christopher, M. (1998), Logistics and Supply Chain Management - Strategies for reducing Cost and Improving Service, Financial times Professional Ltd., London.

Cohendet, P. and Llerena, P. (1990), "Nature de l'information, évaluation et organisation de l'entreprise", Revue d'Economie Industrielle, n 51, p.141-165.

Cohendet, P. and Llerena, P. (1999), "Flexibilité et modes d'organisation", Revue Française de Gestion, mars-avril-mai 1999, p.72-79.

Cooper, M., Lambert, D. and Pagh, J. (1997), "Supply Chain Management: More Than a New Name for Logistics", The International Journal of Logistics Management, 8,1,1-14

Croom, S., Romano, P. and Giannakis, M. (2000), "Supply chain management: an analytical framework for critical literature review", European Journal of Purchasing \& Supply Chain Management, Vol.6, $\mathrm{n}^{\circ} 1, \mathrm{pp} .67-83$.

Ellram, L.M. (1991), "Supply chain management: the industrial organisation perspective", International Journal of Physical Distribution and Logistics Management, Vol.21, $\mathrm{n}^{\circ} 1$, pp.13-22.

Ellram, L.M. (1996), "The use of the case study method in logistics research", Journal of Business Logistics, Vol 17, No 2, pp. 93-138.

Fabbe-Costes, N. (1997), "L'intervention de la logistique dans la formulation / mise en acte de la stratégie en milieu complexe", in Avenier, M.J., La stratégie "Chemin Faisant", Economica, Paris, pp. 239-267.

Fabbe-Costes, N. and Brulhart, F. (1999), "Fonctionnement en réseau de partenaires : conditions de réussite", Revue Française de Gestion Industrielle, Vol. 18, Nº1, 1999, pp.31-46.

Fabbe-Costes, N. (2002), "Évaluer la création de valeur du Supply Chain Management", Logistique et Management, Vol.10 - º1 - 2002, pp.29-36.

Fabbe-Costes, N. and Lièvre, P. (dir.) (2002), Ordres et désordres en logistique, Hermès Science Publications - Lavoisier, Paris.

Fabbe-Costes, N. and Colin, J. (2003), "Formulating a logistics strategy", in Waters, D., Global logistic and distribution planning - Strategies for management, 4th edition, Kogan Page, London, U.K., pp. 82 à 103.

Gadde, L. E. and Håkansson, H. (2001), Supply Network Strategies, John Wiley \& Sons, Chicester. 
Gadde, L.-E., Håkansson, M., Jahre, M. and Persson, G. (2002), "'More instead of Less' Strategies for the use of logistics resources", Journal on Chain and Network Science, Vol 2, No 2, pp.81-93

Hatteland, C.J. (2002), The roll-rack - a facility case in the Netlog project, Not published.

Hughes, T. (1983), Networks of Power. Electrification in Western Society. 1880-1930. Baltimore: The John Hopkins University Press.

Hughes, T. (1994), "Technological Momentum", in M. Roe Smith and L Marx (eds) Does Technology Drive History? The Dilemma of technological Determinism, Cambridge Mass: The MIT Press..

Håkansson, H. and Snehota, I. (1995), Developing Relationships in Business Networks, Thompson, London.

Jahre, M. and Hatteland, C.J. (2003), The roles of packaging in distribution networks, under review for publication in International Journal of Physical Distribution and Logistics Management.

Johnsson, M. (1999), Packaging Logistics - a value added approach, Department of Technical Logistics, Lund University.

Lambert, D.M., Cooper, M.C. and Pagh, J.D. (1998), "Supply Chain Management: Implementation Issues and Research Opportunities", The International Journal of Logistics Management, Vol 9, No 2, pp. 1-19

Larson, P.D. and Dale, S.R. (1998), "Supply Chain Management: definition, growth and approaches", Journal of Marketing Theory and Practice, Vol.6, n4, pp.1-5

Mentzer, J.T., DeWitt, W., Keebler, J.S., Min, S., Nix, N.W., Smith, C.D. and Zacharia, Z.G. (2001), "Defining Supply Chain Management", Journal of Business Logistics, Vol 22, No 2, pp. 1-25.

Orton, J.D. and Weick, K. E. (1990),"Loosely Coupled Systems: A Reconceptualization", Academy of Management Review, Vol 15, No 2, pp. 203-233

Paché, G. and Colin, J. (2000) "Recherche et applications en logistique: des questions d'hier et d'aujourd'hui", in Fabbe-Costes, N. et al. (eds), Faire de la recherche en logistique et distribution?, Vuibert-Fnege, Paris, p.31-53.

Penrose, E. (1959, 1995), The Theory of the Growth of the Firm, Oxford University Press, New York.

Piore, M. (1992), Fragments of a Cognitive Theory of Technological Change and Organizational Structure. In Nohria, N. and Eccles, R. (eds.) Networks and Organizations. Structure, Form and Action. Harvard Business School, Boston.

Stock, J. R. and Lambert, D.M. (2001), Strategic Logistics Management, McGraw-Hill Companies, Inc., New York.

Uzzi, B. (1997), "Social Structure and Competition in Interfirm networks: The Paradox of Embeddedness", Administrative Science Quarterly, 42, pp. 35-67.

Weick, K. E. (1982),"Management of Organisational Change among loosely coupled elements", in P. S. e. a. Goodman, Change in Organisations, Jossey Bass, San Franscisco, pp.375-408.

Wernerfeldt, B. (1984), "A resource based view of the firm", Strategic Management Journal, Vol 5, pp. 171-180. 